\title{
Variations in Functional and Anatomical Outcomes and in Proliferative Vitreoretinopathy Rate along a Prospective Collaborative Study on Primary Rhegmatogenous Retinal Detachments: The Retina 1 Project-Report 4
}

\author{
J. Carlos Pastor, ${ }^{1,2,3}$ Itziar Fernández, ${ }^{1,3}$ Rosa M. Coco, ${ }^{1}$ María R. Sanabria,, 4 \\ Enrique Rodríguez de la Rúa, ${ }^{1,5}$ Rosa M. Piñon, ${ }^{6}$ Vicente Martinez, ${ }^{7}$ \\ Anna Sala-Puigdollers, ${ }^{1,2}$ José M. Gallardo, ${ }^{8}$ and Sara Velilla ${ }^{9}$ \\ ${ }^{1}$ Institute of Applied Ophthalmobiology (IOBA), University of Valladolid, 47011 Valladolid, Spain \\ ${ }^{2}$ Department of Ophthalmology, Hospital Clínico Universitario de Valladolid, 47005 Valladolid, Spain \\ ${ }^{3}$ Ciber BBN, 50018 Zaragoza, Spain \\ ${ }^{4}$ Department of Ophthalmology, Complejo Asistencial de Palencia (CAPA), 34005 Palencia, Spain \\ ${ }^{5}$ Department of Ophthalmology, Hospital Universitario Puerta del Mar, 11009 Cádiz, Spain \\ ${ }^{6}$ Department of Ophthalmology, Hospital General Universitario de Burgos, 09005 Burgos, Spain \\ ${ }^{7}$ Department of Ophthalmology, Hospital Vall d'Hebrón, 08035 Barcelona, Spain \\ ${ }^{8}$ Department of Ophthalmology, Hospital Reina Sofia, 14004 Córdoba, Spain \\ ${ }^{9}$ Department of Ophthalmology, Hospital San Millán, 26006 Logroño, Spain
}

Correspondence should be addressed to J. Carlos Pastor, pastor@ioba.med.uva.es

Received 6 September 2012; Accepted 26 September 2012

Academic Editors: Y. F. Shih and M. Sugimoto

Copyright (๑) 2012 J. Carlos Pastor et al. This is an open access article distributed under the Creative Commons Attribution License, which permits unrestricted use, distribution, and reproduction in any medium, provided the original work is properly cited.

\begin{abstract}
Purpose. To analyse variations in the anatomical and functional outcomes and in proliferative vitreoretinopathy (PVR) rate of a prospective multicentric study that was primarily designed for identification of clinical risk factors for PVR. Methods. 1,046 retinal detachment $(\mathrm{RD})$ cases were analysed. Cases were divided into two series based upon variation in PVR rate determined by logistic regression analysis. Series 1 (S1) included RD treated during 2004-2005 $(n=481)$ and Series 2 (S2) during 2006-2008 $(n=565)$. Pre-, intra-, and postoperative characteristics were recorded. Results. There were few differences in the preoperative characteristics. S2 had more vitrectomies and scleral bands and fewer explants and associated cataract extractions than S1. Anatomic reattachment improved from $87.9 \%$ to $92.9 \%$ in S1 and S2, respectively, $(P=0.006)$. Visual acuity at 3 months $\geq 20 / 40$ increased from $36.5 \%$ of S1 to $44.2 \%$ in S2 $(P=0.049)$. PVR rate diminished from $14.1 \%$ in S1 to $8.1 \%$ in S2 $(P=0.002)$. Centres with higher rates of PVR in S1 showed the greatest reductions in S2. Conclusion. An improvement in anatomical and functional outcome and PVR rate occurred in participating centres cannot be attributed to the learning curve of surgeons. We speculated that it could be an effect of their participation in the study.
\end{abstract}

\section{Introduction}

In 2005, after a retrospective case-controlled study involving five clinical centres, we developed a formula to estimate the risk of proliferative vitreoretinopathy (PVR) onset after rhegmatogenous retinal detachment $(\mathrm{RD})$ surgery [1]. Even though the sensitivity and specificity values of that formula were higher than other predictive formulas [2], it was not considered appropriate for routine clinical use. Thus the
Retina 1 project was designed to improve that predictive formula by increasing the sample. This project consisted of a prospective study involving 17 centres in Spain and Portugal that collected pre-, intra-, and postoperative data for consecutive, noncomplicated RDs for over 1,000 cases between 2004 and 2008.

Statistical analysis of the collected data performed after closing the recruitment period revealed an inflexion point indicating a significant reduction in PVR rate at the end 
of 2005. Careful analysis of the pre- and post-2005 data also showed improvements in reattachment rate which could not be attributed to differences in preoperative and intraoperative characteristics. Thus, we hypothesized that active collaborative participation of surgeons in the project might have had a positive influence in their outcomes.

Although the main purpose of the Retina 1 project was to increase the information on the clinical characteristics which contribute to a PVR development after RD, we consider that these partial results are interesting because they emphasize some of the positive effects of any multicentric study. Therefore, the main purpose of this paper is to offer the anatomical and functional outcomes and PVR rate in one of the largest prospective series of $\mathrm{RD}$ and to analyze the variations during the lapse of this study.

\section{Methods}

2.1. Patient Population. The protocol for this study was approved by the ethics committee of the coordinating centre (IOBA, University of Valladolid) and of each participant institution. Informed consent for RD surgery specifically included a statement of the use of data for this project. This research followed the tenets of the Declaration of Helsinki. All participating surgeons had enough experience in treating $\mathrm{RD}$ (minimum of 5 years of experience and at least $100 \mathrm{RD}$ cases treated annually), and they were allowed to decide the surgical approach of any case according to their personal experience. A total of 69 surgeons were involved in this study. Periodically the surgeons received information regarding their partial outcomes, and they met at intervals to analyse the results.

Updated information was sent to all participants every six months, and the coordinating centre was continuously in touch with the other centres to resolve questions about how to fill in the data collection forms. The study started in October 2004 and ended in February 2008. During this period, a total of 1,046 consecutive cases of RD fulfilling the inclusion criteria were enrolled by the different centres: 14 cases in 2004 (1.24\%), 467 in 2005 (44.6\%), 288 in 2006 (27.5\%), 259 in 2007 (24.7\%), and 18 in 2008 (1.72\%).

2.2. Inclusion and Exclusion Criteria. All patients admitted for surgery with primary RD with a followup of 3 months were considered for inclusion. Cases with preoperative PVR grade C-1 or higher according to the Retina Society classification [3] were excluded. Cases in which the RD was due to perforating injury were also excluded.

2.3. Variables. A total of 83 pre-, intra-, and postoperative clinical characteristics that were gathered in the Retina 1 project were used in this paper $[4,5]$. To analyse variations in these characteristics, the patients were divided into two series. Series 1 (S1) was composed of those patients treated before and throughout $2005(n=481)$, and Series 2 (S2) included those treated between 2006 and $2008(n=565)$ because of the statistically significant variation observed at the end of 2005 (see below).
2.4. Statistical Analysis. Quantitative results were expressed as means \pm standard deviations, and qualitative variables were described in percentages and absolute frequencies. The two series, S1 and S2, were defined according to the year in which the patients were treated based upon the results of a logistic regression model that related the rate of PVR with the year of surgery. Student's $t$-test for independent samples was used to compare each series with quantitative characteristics. Qualitative variables were compared with the $\chi^{2}$ test. The Fisher exact test was used on sparse contingency tables. Statistical significance was established at the $0.05 \%$ confidence level. The statistical analysis was performed with SPSS 15.0 for Windows (SPSS Inc., Chicago, IL, USA).

\section{Results}

Logistic regression analysis showed that there was a significant relationship between the PVR rate and year of treatment $(P=0.008)$. The rates of PVR were relatively stable during 2004 and 2005. However after that year, the rate was reduced by about half. Based on this fact, we analysed patient data divided into periods S1, 2004 to 2005, and S2, 2006 to 2008. Both series were composed by an adequate number of patients for statistical analysis (S1: $n=481$ and S2: $n=565$ ). For these series, there were no significant differences in age (S1: $57.7 \pm 15.1$ years; S2: $57.2 \pm 15.9$ years), time between the beginning of symptoms and surgery (S1: 15.4 days \pm 27.8 ; S2: $18.1 \pm 43.1$ days), or preoperative intraocular pressure ( $\mathrm{S} 1$ : $13.3 \pm 3.4 \mathrm{mmHg}$; S2: $13.3 \pm 4.5 \mathrm{mmHg}$ ).

Macula-on cases were more frequent in S2, 39.7\%, than in $\mathrm{S} 1,33.1 \%,(P=0.029$, Table 1$)$. Previous $\mathrm{RD}$ surgery was less common in S2, 8.9\%, than in S1, 12.6\%, although the difference was not significant $(P=0.06)$.

There were several intraoperative characteristics that distinguished the S1 and S2 series. There were more S2 cases in which a scleral band was used during pars plana vitrectomy, 59.6\%, than in S1, 44,4\% $(P<0.001$, Table 2$)$. Explants were less common in S2, 7\%, than in S1, $11.6 \%$ $(P=0.01)$. Also, combined cataract extraction in $\mathrm{S} 2,7.3 \%$, was less frequent than in $\mathrm{S} 1,12.6 \%(P=0.004)$.

Postoperative characteristics were assessed at the last follow-up visit at three months after surgery (Table 3 ). The reattachment rate at that time was significantly higher in S2, $92.9 \%$, than in S1, $87.9 \%(P=0.006)$. Visual acuity at 3 months was also better, $\geq 20 / 40$ in $36.5 \%$ of $S 1$ patients and $44.2 \%$ in S2 patients $(P=0.049)$. The PVR rate diminished from $14.1 \%$ in $S 1$ patients to $8.1 \%$ in S2 patients $(P=0.002)$.

Retrospectively, we defined three different groups of centres depending on the final PVR rates. Group 1 (G1) had a final PVR rate less than 9\%, Group 2 (G2) between 10\% and $13 \%$, and Group $3(\mathrm{G} 3)$ had a PVR rate higher than $13 \%$ (Table 4). There was no significant difference between S1 and S2 in G1 the PVR rates $(P=0.95)$. However, PVR S2 rates in G2 and G3 decreased significantly compared to S1 rates $(P=0.043$ and $P=0.041$, resp.). The number of surgeons involved in both series was 43 and although there were some variations, most of them were the same during the entire study. Further, most of them had more than 300 $\mathrm{RD}$ surgeries at the beginning of the project. 
Table 1: Preoperative characteristics.

\begin{tabular}{|c|c|c|c|c|c|}
\hline \multirow{3}{*}{ Characteristic } & \multirow{2}{*}{\multicolumn{2}{|c|}{$\begin{array}{c}\text { S1 } \\
2004-2005\end{array}$}} & \multirow{2}{*}{\multicolumn{2}{|c|}{$\begin{array}{c}\text { S2 } \\
2006-2008\end{array}$}} & \multirow{3}{*}{$P$ value } \\
\hline & & & & & \\
\hline & $N(\%)$ & $95 \% \mathrm{CI}$ & $N(\%)$ & $95 \% \mathrm{CI}$ & \\
\hline Previous PVR & $230(47.8 \%)$ & $43.4 \%-52.3 \%$ & $295(52.2 \%)$ & $48.1 \%-56.3 \%$ & \\
\hline Retinal break & & & & & 0.062 \\
\hline Tear & $348(72.5 \%)$ & $68.5 \%-76.5 \%$ & $391(69.3 \%)$ & $65.5 \%-73.1 \%$ & \\
\hline Hole & $86(17.9 \%)$ & $14.5 \%-21.3 \%$ & $137(24.3 \%)$ & $20.8 \%-27.8 \%$ & \\
\hline Dialysis & $6(1.3 \%)$ & $0.3 \%-2.2 \%$ & $6(1.1 \%)$ & $0.2 \%-1.9 \%$ & \\
\hline Giant tear & $20(4.2 \%)$ & $2.4 \%-6 \%$ & $16(2.8 \%)$ & $1.5 \%-4.2 \%$ & \\
\hline Not visible & $20(4.2 \%)$ & $2.4 \%-6 \%$ & $14(2.5 \%)$ & $1.2 \%-3.8 \%$ & \\
\hline Type of break & & & & & 0.264 \\
\hline Unique & $232(50.2 \%)$ & $45.7 \%-54.8 \%$ & $293(53.7 \%)$ & $49.5 \%-57.8 \%$ & \\
\hline Multiple & $204(44.2 \%)$ & $39.6 \%-48.7 \%$ & $228(41.8 \%)$ & $37.6 \%-45.9 \%$ & \\
\hline Posterior & $6(1.3 \%)$ & $0.3 \%-2.3 \%$ & $11(2 \%)$ & $0.8 \%-3.2 \%$ & \\
\hline Not visible & $20(4.3 \%)$ & $2.5 \%-6.2 \%$ & $14(2.6 \%)$ & $1.2 \%-3.9 \%$ & \\
\hline Size of breaks (clock hours) & & & & & 0.242 \\
\hline $0-1$ & $318(66.9 \%)$ & $62.7 \%-71.2 \%$ & $355(64.2 \%)$ & $60.2 \%-68.2 \%$ & \\
\hline $2-3$ & $112(23.6 \%)$ & $19.8 \%-27.4 \%$ & $153(27.7 \%)$ & $23.9 \%-31.4 \%$ & \\
\hline$>3$ & $25(5.3 \%)$ & $3.3 \%-7.3 \%$ & $31(5.6 \%)$ & $3.7 \%-7.5 \%$ & \\
\hline Not visible & $20(4.2 \%)$ & $2.4 \%-6 \%$ & $14(2.5 \%)$ & $1.2 \%-3.8 \%$ & \\
\hline Vitreous hemorrhage & $43(9 \%)$ & $6.4 \%-11.6 \%$ & $81(14.6 \%)$ & $11.7 \%-17.6 \%$ & 0.006 \\
\hline Extension RD (quadrants) & & & & & 0.432 \\
\hline $0-1$ & $80(16.7 \%)$ & $13.4 \%-20 \%$ & $108(19.3 \%)$ & $16 \%-22.5 \%$ & \\
\hline $2-3$ & $341(71.2 \%)$ & $67.1 \%-75.2 \%$ & $395(70.4 \%)$ & $66.6 \%-74.2 \%$ & \\
\hline 4 & $58(12.1 \%)$ & $9.2 \%-15 \%$ & $58(10.3 \%)$ & $7.8 \%-12.9 \%$ & \\
\hline Macula-on & $158(33.1 \%)$ & $28.9 \%-37.3 \%$ & $223(39.7 \%)$ & $35.6 \%-43.7 \%$ & 0.029 \\
\hline Choroidal detachment & $3(0.6 \%)$ & $0 \%-1.3 \%$ & $11(2 \%)$ & $0.8 \%-3.1 \%$ & 0.062 \\
\hline Previous uveitis & $25(5.2 \%)$ & $3.2 \%-7.2 \%$ & $58(10.4 \%)$ & $7.9 \%-12.9 \%$ & 0.002 \\
\hline Previous surgery for RD & $60(12.6 \%)$ & $9.6 \%-15.5 \%$ & $50(8.9 \%)$ & $6.6 \%-11.3 \%$ & 0.062 \\
\hline Previous PPV & $28(5.9 \%)$ & $0 \%-11.9 \%$ & $30(5.4 \%)$ & $0 \%-11.8 \%$ & 0.120 \\
\hline Previous scleral surgery & $37(7.7 \%)$ & $0.9 \%-14.6 \%$ & $19(3.4 \%)$ & $0 \%-8.5 \%$ & 0.017 \\
\hline Aphakia & $161(33.5 \%)$ & $29.3 \%-37.8 \%$ & $221(39.2 \%)$ & $35.2 \%-43.2 \%$ & 0.062 \\
\hline PVD & $241(50.1 \%)$ & $45.6 \%-54.6 \%$ & $256(45.4 \%)$ & $41.3 \%-49.5 \%$ & 0.276 \\
\hline Myopia & $187(50.1 \%)$ & $45.1 \%-55.2 \%$ & $244(60.5 \%)$ & $55.8 \%-65.3 \%$ & 0.012 \\
\hline Ocular trauma & $13(2.7 \%)$ & $1.3 \%-4.2 \%$ & $21(3.7 \%)$ & $2.2 \%-5.3 \%$ & 0.357 \\
\hline Previous ocular surgeries other than RD & $198(41.2 \%)$ & $36.8 \%-45.6 \%$ & $263(46.6 \%)$ & $42.5 \%-50.7 \%$ & 0.080 \\
\hline $\mathrm{RD}$ in fellow eye & $38(7.9 \%)$ & $5.5 \%-10.4 \%$ & $44(7.8 \%)$ & $5.6 \%-10 \%$ & 0.945 \\
\hline PVR in fellow eye & $39(8.4 \%)$ & $5.9 \%-10.9 \%$ & $18(3.2 \%)$ & $1.8 \%-4.7 \%$ & $<0.001$ \\
\hline Previous VA & & & & & 0.051 \\
\hline$<20 / 100$ & $305(65 \%)$ & $60.7 \%-69.3 \%$ & $325(57.6 \%)$ & $53.5 \%-61.7 \%$ & \\
\hline $20 / 100-20 / 40$ & $59(12.6 \%)$ & $9.6 \%-15.6 \%$ & $83(14.7 \%)$ & $11.8 \%-17.7 \%$ & \\
\hline$\geq 20 / 40$ & $105(22.4 \%)$ & $18.7 \%-26.2 \%$ & $156(27.7 \%)$ & $24 \%-31.4 \%$ & \\
\hline DM & $33(7.1 \%)$ & $4.8 \%-9.4 \%$ & $52(9.5 \%)$ & $7 \%-11.9 \%$ & 0.170 \\
\hline RD family history & $15(4.4 \%)$ & $2.2 \%-6.5 \%$ & $33(7.6 \%)$ & $5.1 \%-10.1 \%$ & 0.075 \\
\hline PVR family history & $2(0.6 \%)$ & $0 \%-1.5 \%$ & $9(2.2 \%)$ & $0.8 \%-3.6 \%$ & 0.123 \\
\hline
\end{tabular}

$N$ (\%): number and percent of proliferative vitreo-retinopathy (PVR) cases; CI: confidence interval; macula-on: retinal detachment with macula attached; PPV: pars plana vitrectomy; PVD: posterior vitreous detachment; myopia: negative refractive error of any value; VA: visual acuity measured with Snellen test with pinhole if necessary; DM: diabetes mellitus. 
TABLE 2: Intraoperative characteristics.

\begin{tabular}{|c|c|c|c|c|c|}
\hline \multirow{3}{*}{ Characteristics } & \multirow{2}{*}{\multicolumn{2}{|c|}{$\begin{array}{c}\text { S1 } \\
2004-2005\end{array}$}} & \multicolumn{2}{|c|}{ S2 } & \multirow{3}{*}{$P$ value } \\
\hline & & & & & \\
\hline & $N(\%)$ & $95 \% \mathrm{CI}$ & $N(\%)$ & $95 \% \mathrm{CI}$ & \\
\hline PPV & $385(80 \%)$ & $76.5 \%-83.6 \%$ & $446(79.1 \%)$ & $75.7 \%-82.4 \%$ & 0.660 \\
\hline Scleral band & $243(50.6 \%)$ & $46.2 \%-55.1 \%$ & $346(61.3 \%)$ & $57.3 \%-65.4 \%$ & $<0.001$ \\
\hline PPV associated with band & $171(44.4 \%)$ & $39.5 \%-49.4 \%$ & $266(59.6 \%)$ & $55.1 \%-64.2 \%$ & $<0.001$ \\
\hline Explant & $55(11.6 \%)$ & $8.7 \%-14.5 \%$ & $39(7 \%)$ & $4.9 \%-9.1 \%$ & 0.010 \\
\hline Retinopexy (cryo) & $16(3.4 \%)$ & $1.8 \%-5.1 \%$ & $28(5.1 \%)$ & $3.2 \%-6.9 \%$ & 0.205 \\
\hline Cryotherapy (clock hours) & & & & & 0.326 \\
\hline 1 & $92(22 \%)$ & $18 \%-26 \%$ & $115(21 \%)$ & $17.6 \%-24.4 \%$ & \\
\hline 2 & $42(10 \%)$ & $7.1 \%-12.9 \%$ & $65(11.9 \%)$ & $9.2 \%-14.6 \%$ & \\
\hline$>2$ & $16(3.8 \%)$ & $2 \%-5.7 \%$ & $33(6 \%)$ & $4 \%-8 \%$ & \\
\hline No & $269(64.2 \%)$ & $59.6 \%-68.8 \%$ & $335(61.1 \%)$ & $57.1 \%-65.2 \%$ & \\
\hline External drainage & $55(11.6 \%)$ & $8.7 \%-14.4 \%$ & $63(11.3 \%)$ & $8.6 \%-13.9 \%$ & 0.878 \\
\hline Tamponade agent & & & & & 0.039 \\
\hline Air & $47(9.9 \%)$ & $7.2 \%-12.5 \%$ & $31(5.5 \%)$ & $3.6 \%-7.4 \%$ & \\
\hline SF6 & $187(39.2 \%)$ & $34.8 \%-43.6 \%$ & $226(40.4 \%)$ & $36.3 \%-44.4 \%$ & \\
\hline C3F8 & $191(40 \%)$ & $35.6 \%-44.4 \%$ & $219(39.1 \%)$ & $35.1 \%-43.1 \%$ & \\
\hline Silicone oil & $22(4.6 \%)$ & $2.7 \%-6.5 \%$ & $37(6.6 \%)$ & $4.5 \%-8.7 \%$ & \\
\hline No & $30(6.3 \%)$ & $4.1 \%-8.5 \%$ & $48(8.6 \%)$ & $6.3 \%-10.9 \%$ & \\
\hline Laser (extension in clock hours) & & & & & $<0.001$ \\
\hline $0-2$ & $284(60 \%)$ & $55.6 \%-64.5 \%$ & $244(43.6 \%)$ & $39.5 \%-47.7 \%$ & \\
\hline $3-5$ & $86(18.2 \%)$ & $14.7 \%-21.7 \%$ & $114(20.4 \%)$ & $17.1 \%-23.7 \%$ & \\
\hline $6-8$ & $35(7.4 \%)$ & $5.1 \%-9.8 \%$ & $48(8.6 \%)$ & $6.3 \%-10.9 \%$ & \\
\hline$\geq 9$ & $68(14.4 \%)$ & $11.2 \%-17.6 \%$ & $154(27.5 \%)$ & $23.8 \%-31.2 \%$ & \\
\hline PFCL & $310(65.1 \%)$ & $60.8 \%-69.4 \%$ & $376(66.9 \%)$ & $63 \%-70.8 \%$ & 0.543 \\
\hline Retinotomy & $28(5.9 \%)$ & $3.8 \%-8 \%$ & $38(6.7 \%)$ & $4.7 \%-8.8 \%$ & 0.561 \\
\hline Retinectomy & $8(1.7 \%)$ & $0.5 \%-2.9 \%$ & $3(0.5 \%)$ & $0 \%-1.2 \%$ & 0.071 \\
\hline Choroidal hemorrhage & $6(1.3 \%)$ & $0.3 \%-2.3 \%$ & $13(2.3 \%)$ & $1.1 \%-3.6 \%$ & 0.212 \\
\hline Intravitreal hemorrhage & $18(3.8 \%)$ & $2.1 \%-5.5 \%$ & $26(4.6 \%)$ & $2.9 \%-6.4 \%$ & 0.518 \\
\hline Cataract extraction associated & $60(12.6 \%)$ & $9.6 \%-15.6 \%$ & $41(7.3 \%)$ & $5.2 \%-9.5 \%$ & 0.004 \\
\hline IOL & $49(10.3 \%)$ & $7.6 \%-13.1 \%$ & $33(5.9 \%)$ & $3.9 \%-7.8 \%$ & 0.009 \\
\hline
\end{tabular}

$N(\%)$ : number and percent of proliferative vitreo-retinopathy cases; CI: confidence interval; PPV: pars plana vitrectomy; PFCL: perfluorocarbon liquid intraoperative use; IOL: intraocular lens implantation during surgery.

TABLE 3: Postoperative characteristics.

\begin{tabular}{|c|c|c|c|c|c|}
\hline & \multirow{2}{*}{\multicolumn{2}{|c|}{$\begin{array}{c}\text { S1 } \\
2004-2005\end{array}$}} & \multicolumn{2}{|c|}{ S2 } & \multirow{3}{*}{$P$ value } \\
\hline & & & \multicolumn{2}{|c|}{$2006-2008$} & \\
\hline & $N(\%)$ & $95 \% \mathrm{CI}$ & $N(\%)$ & $95 \% \mathrm{CI}$ & \\
\hline Uveitis* & $324(67.8 \%)$ & $63.6 \%-72 \%$ & $379(67.8 \%)$ & $63.9 \%-71.7 \%$ & 0.972 \\
\hline Retina reattachment rate & $423(87.9 \%)$ & $85 \%-90.9 \%$ & $525(92.9 \%)$ & $90.8 \%-95 \%$ & 0.006 \\
\hline PVR rate & $68(14.1 \%)$ & $11 \%-17.3 \%$ & $46(8.1 \%)$ & $5.9 \%-10.4 \%$ & 0.002 \\
\hline Choroidal detachment ${ }^{\dagger}$ & $4(0.8 \%)$ & $0 \%-1.7 \%$ & $17(3 \%)$ & $1.6 \%-4.5 \%$ & 0.012 \\
\hline Postoperative VA & & & & & 0.049 \\
\hline$<20 / 100$ & $109(25.2 \%)$ & $21.1 \%-29.3 \%$ & $122(22.6 \%)$ & $19.1 \%-26.2 \%$ & \\
\hline $20 / 100-20 / 40$ & $167(38.6 \%)$ & $34 \%-43.2 \%$ & $179(33.3 \%)$ & $29.3 \%-37.3 \%$ & \\
\hline$\geq 20 / 40$ & $158(36.5 \%)$ & $32 \%-41 \%$ & $238(44.2 \%)$ & $40 \%-48.4 \%$ & \\
\hline
\end{tabular}

$N(\%)$ : number and percent of proliferative vitreo-retinopathy (PVR) cases; CI: confidence interval; VA: best visual acuity corrected at the end of followup (Snellen charts); ${ }^{*}$ during the first month of followup; ${ }^{\dagger}$ during the first $24 \mathrm{~h}$ after surgery. 
TABLE 4: PVR rate according to three groups of centers.

PVR rate

\begin{tabular}{|c|c|c|c|c|c|c|}
\hline \multirow[t]{3}{*}{ Centers $(N)$} & \multirow[t]{3}{*}{ Patients per center } & \multicolumn{2}{|c|}{ S1 } & \multicolumn{2}{|c|}{$\mathrm{S} 2$} & \multirow[t]{3}{*}{$P$ value } \\
\hline & & \multicolumn{2}{|c|}{ 2004-2005 } & \multicolumn{2}{|c|}{ 2006-2008 } & \\
\hline & & $N(\%)$ & $95 \%$ CI & $N(\%)$ & $95 \% \mathrm{CI}$ & \\
\hline G1 (8) & $60 \pm 31$ & $10(4.9 \%)$ & $1.9 \%-7.9 \%$ & $17(6.1 \%)$ & $3.3 \%-8.9 \%$ & 0.956 \\
\hline G2 (3) & $67.33 \pm 33$ & $13(15.9 \%)$ & $7.9 \%-23.8 \%$ & $7(5.8 \%)$ & $1.6 \%-10 \%$ & 0.043 \\
\hline G3 (6) & $60.5 \pm 58$ & $45(23 \%)$ & $17.1 \%-28.8 \%$ & $22(13.2 \%)$ & $8 \%-18.3 \%$ & 0.041 \\
\hline
\end{tabular}

PVR: proliferative vitreo-retinopathy; $N$ (\%): number and percent of PVR cases; CI: confidence interval; G1: <9\% final PVR rate; G2: 9-13\% final PVR rate; G3: $\geq 13 \%$ final PVR rate.

\section{Discussion}

Anatomical and functional results after primary noncomplicated RD surgery are now relatively stable in most of the published series, and recent papers show data that could be considered as reference results for many clinicians to analyse the quality of their practices. One such study, under the auspices of the Royal College of Ophthalmologists, consisted of a nationwide cross-sectional survey of $768 \mathrm{RD}$ patients attended by 167 consultant ophthalmologists [6]. That report showed an overall reattachment rate with a single procedure was $77 \%$. There were significant differences in reattachment rates between specialists, $82 \%$, and nonspecialists, $71 \%$, with a single surgery [6]. Our series (Retina 1) results were similar when compared to the specialist groups, probably because surgeries in Retina 1 were performed by experienced surgeons in all of the participating centres. The overall reattachment rate was over $88 \%$ after a single procedure and $90 \%$ at the end of followup $[4,5,7]$.

As mentioned, the analysis of PVR rate showed a significant reduction after the end of 2005. Then the overall sample was divided into 2 series and there was a significant improvement in the retina reattachment and PVR rates in the S2 patients compared to the $\mathrm{S} 1$ patients. This was also reflected in the improvement of final visual acuity after followup. Many factors have been implicated in the improvement of outcomes after RD surgery, including the learning curve of surgeon $[8,9]$, changes in surgical technique from the scleral procedures to vitrectomy [5], and others. Between the S1 and S2 patient populations, there were only a few differences in the preoperative characteristics and most of the involved surgeons were the same. In the S2 series, there were more previous cases of PVR with grades A or B and previous cases of uveitis. These changes could be attributed to a better examination of the patients, because of the requisites of the inclusion criteria, and have been already reported [5]. There were also more macula-on cases in S2, although there were no differences in the evolution time between symptoms onset and surgery. In a previous partial report from the Retina 1 project, some presurgery factors were statistically related to the visual outcome [5]. Among them, the status of the macula and the existence of previous ocular surgeries other than RD influence final vision outcome. Because they were slightly more macula-on cases in S2, this fact could have influenced the final visual acuity.
There were more cases with previous ocular surgery other than RD in S2, although the differences were not significant. Among the ocular surgeries the most frequent is cataract which is been more important because of the ageing of the population. Also more myopic eyes were treated in S2 and less PVR cases in the fellow eye were present in S2. We have not found any explanation for these findings, and we consider that they have no relevant influence on final outcomes.

There were also some differences in surgical techniques in both series. The S2 population had more scleral bands associated with vitrectomy, more laser intervention in larger extensions of the retina, and more silicone oil injections. Other differences included fewer explants and concomitant cataract extractions in the S2, less cases of use of air as a tamponade agent in S2 and more cases of silicone oil in $\mathrm{S} 2$. These surgical differences for managing $\mathrm{RD}$ have been already reported by our group, and they do not respond to an improvement strategy but to a global change in the approaching of this disease [5]. However, the changes in the surgical approach for RD notice during the time of this project were less dramatic than those that occurred during the early years of 2000. According to our data, they did not influence the anatomical outcome comparing a short period of time of the whole prospective study (the first three years) [5]. We did not incorporate information on the vitrectomy techniques used during the study, therefore a possible bias for the use of $23 \mathrm{G}$ and $25 \mathrm{G}$ instruments on the later cases might have influenced the results [10-12].

Therefore, the improvement in anatomical rate and decrease in PVR rate cannot be attributed to neither the management of less complicated cases after 2005 nor the changes in the surgical approach. Because most of the participating surgeons were the same throughout the study and all were considered experienced at the beginning of the study, the improvements that we observed cannot be attributed to their learning curve. In seeking an explanation for this improvement we found no published reports suggesting that participation in collaborative studies on RD could influence the final outcomes, although several multicentric series have been published [13-16].

Participating in clinical trials contributes to the improvement in the quality of care delivered to the patients [17], and collaborative studies such as Retina 1 may share some of the common positive aspects of those studies. During the 
four years of the project, surgeons attended several specific meetings organized by the coordinating centre, received periodically (every 6 months) information on their personal results, and once a year they discussed the global results. These actions may have had some beneficial influence in the preoperative examination, in some changes in surgical techniques, and in the overall management of RD patients.

The prospective collection of data could have also contributed to a better examination of the eyes because it promoted the entry of more complete and accurate information into the project data collection forms. In this sense, there were differences in several clinical characteristics of the RD that could be attributed to a better preoperative examination of the patients. For instance, in the S2 population there were fewer cases of nonvisible retinal breaks, more preoperative uveitis, more familial cases of $\mathrm{RD}$, and more preoperative cases of vitreous haemorrhages.

In S1, $12.5 \%$ of the patients had previous RD surgery in other centres. That percentage fell to $8.9 \%$ in S2, which approached statistical significance. Additionally, significantly fewer patients in the S2 group had previous scleral surgery compared to the S1 group. Because most of the participant centres were integrated in the National Health Systems of Spain and Portugal, these facts can be interpreted as the recognition of the reference condition for $\mathrm{RD}$ treatment by the surrounding general ophthalmologists maybe as also an effect of the participation in this study.

Visual outcome also showed a significant improvement that could be explained in part by the slight higher rate of macula-on cases in S2 and the lower PVR rate. A limitation of this study was the procedure used for judgment of anatomical reattachment. At the onset of the project, not all centres had optical coherence tomography (OCT) instrumentation. In these centres, the status of the macula and reattachment after surgery were clinically judged by indirect ophthalmoscopy and biomicroscopic examination of the fundus. If OCT had been available, some cases with poor visual acuity would likely be attributed to persistent subretinal fluid [18].

When we grouped centres according the final rates of PVR, we observed that those centres having the medium and highest rates (G2 and G3) had significant reductions in the rates after 2005. It is not the purpose of this study to analyse the reasons for these changes. Nevertheless, it is obvious that in some centres the rates at the onset of the project were inadequate elevated for a referral hospital. We hypothesize that the surgical approaches used and/or the previous examinations were not adequate. However, the final PVR rates of those centres, which were less than half of the initial ones, reinforces our hypothesis that participation in collaborative studies has a positive influence in patient's care.

The relative stability in PVR rate in G1 centres may also support our idea that this complication has a genetic base that cannot be avoided even with a refinement of the surgical technique [19] or increasing the surgeon's experience. Thus as another conclusion of this work, a PVR rate of $6 \%$ could be considered as a reference of care quality for those centers managing RD patients.

Overall, the entire series showed a significant improvement in anatomical and functional outcomes and a clear drop in PVR rate. These improvements could be attributable to, among other factors, the continuous exchange of experiences and the feedback that surgeons received. In conclusion, large prospective clinical studies provide a huge amount of useful information and contribute to the improved care that we deliver to our patients. Such studies are difficult to organise, tedious to develop, and require a great cooperative effort. Nevertheless, the participating surgeons and their patients benefit from the sharing of outcome data, techniques, and innovations derived from the collaborative effort.

\section{Acknowledgments}

Retina 1 project participants are as follows. Clinica Barraquer (Barcelona, Spain), Fundación Oftalmológica del Mediterraneo (Valencia, Spain), Hospital Clínico Universitario (Valladolid, Spain), Hospital de Donostia (San Sebastián, Spain), Hospital General Yagüe (Burgos, Spain), Hospital Nuestra Señora de Sonsoles (Avila, Spain), Hospital Ramón y Cajal (Madrid, Spain), Hospital Reina Sofia (Córdoba, Spain), Hospital San Millán (Logroño, Spain), Hospital Sao João (Porto, Portugal), Hospital Universitario de Canarias (Santa Cruz de Tenerife, Spain), Hospital Universitario de Coimbra (Coimbra, Portugal), Hospital Universitario del Rio Hortega (Valladolid, Spain), Hospital General Universitario de Valencia (Valencia, Spain), Hospital Universitari Vall de Hebrón (Barcelona, Spain), Instituto Oftalmológico de Alicante (Alicante, Spain), and Instituto Universitario de Oftalmobiología Aplicada (Valladolid, Spain), the study was coordinated by the Institute of Applied Ophthalmobiology (IOBA), University of Valladolid, Valladolid, Spain. The authors have no proprietary interest and no specific financial support was received. This project was developed under the Thematic Network 03/13 of the Carlos III Institute of Health of Spain.

\section{References}

[1] E. R. De La Rúa, J. C. Pastor, J. Aragón et al., “Interaction between surgical procedure for repairing retinal detachment and clinical risk factors for proliferative vitreoretinopathy," Current Eye Research, vol. 30, no. 2, pp. 147-153, 2005.

[2] R. H. Y. Asaria, C. H. Kon, C. Bunce et al., "How to predict proliferative vitreoretinopathy: a prospective study," Ophthalmology, vol. 108, no. 7, pp. 1184-1186, 2001.

[3] G. Hilton, R. Machemer, and R. Michels, "The classification of retinal detachment with proliferative vitreoretinopathy," Ophthalmology, vol. 90, no. 2, pp. 121-125, 1983.

[4] J. C. Pastor Jimeno, I. Fernández, E. De La Rodríguez Rúa et al., "Surgical outcomes for primary rhegmatogenous retinal detachments in phakic and pseudophakic patients: The Retina 1 Project-Report 2," British Journal of Ophthalmology, vol. 92, no. 3, pp. 378-382, 2008.

[5] E. R. De La Rúa, J. C. Pastor, I. Fernández et al., "Noncomplicated retinal detachment management: variations in 4 years. Retina 1 project; report 1," British Journal of Ophthalmology, vol. 92, no. 4, pp. 523-525, 2008.

[6] J. A. Thompson, M. P. Snead, B. M. Billington, T. Barrie, J. R. Thompson, and J. M. Sparrow, "National audit of the outcome 
of primary surgery for rhegmatogenous retinal detachment. II. Clinical outcomes," Eye, vol. 16, no. 6, pp. 771-777, 2002.

[7] M. R. Sanabria, I. Fernandez, A. Sala-Puigdollers et al., "A propensity score matching application: indications and results of adding scleral buckle to vitrectomy: The Retina 1 Project: Report 3," European Journal of Ophthalmology, vol. 22, pp. 244-253, 2011.

[8] B. Dugas, P. O. Lafontaine, A. Guillaubey et al., "The learning curve for primary vitrectomy without scleral buckling for pseudophakic retinal detachment," Graefe's Archive for Clinical and Experimental Ophthalmology, vol. 247, no. 3, pp. 319-324, 2009.

[9] M. Sagong and W. Chang, "Learning curve of the scleral buckling operation: lessons from the first 97 cases," Ophthalmologica, vol. 224, no. 1, pp. 22-29, 2009.

[10] M. Mura, S. H. Tan, and M. D. De Smet, "Use of 25-gauge vitrectomy in the management of primary rhegmatogenous retinal detachment," Retina, vol. 29, no. 9, pp. 1299-1304, 2009.

[11] S. Kobayashi, S. Sato, M. Inoue et al., "Comparison of 20- and 25-gauge vitrectomy for primary repair of rhegmatogenous retinal detachment," Ophthalmic Surgery Lasers and Imaging, vol. 41, no. 5, pp. 550-554, 2010.

[12] T. Sandinha, C. de Souza, R. Essex, T. L. Kelly, S. Lake, and R. Phillips, "Revisiting transconjunctival sutureless 25-gauge vitrectomy: still worthwhile?" Clinical and Experimental Ophthalmology, vol. 37, no. 7, pp. 649-653, 2009.

[13] D. Mitry, J. Singh, D. Yorston et al., "The predisposing pathology and clinical characteristics in the Scottish retinal detachment study," Ophthalmology, vol. 118, no. 7, pp. 1429-1434, 2011.

[14] N. Heussen, N. Feltgen, P. Walter et al., "Scleral buckling versus primary vitrectomy in rhegmatogenous retinal detachment study (SPR Study): predictive factors for functional outcome. Study report no. 6.," Graefe's Archive for Clinical and Experimental Ophthalmology, vol. 249, pp. 1129-1136, 2011.

[15] C. I. Falkner-Radler, J. S. Myung, S. Moussa et al., "Trends in primary retinal detachment surgery: results of a bicenter study," Retina, vol. 31, no. 5, pp. 928-936, 2011.

[16] U. Thelen, S. Amler, N. Osada, and H. Gerding, "Outcome of surgery after macula-off retinal detachment-results from MUSTARD, one of the largest databases on buckling surgery in Europe Results from a large German case series," Acta Ophthalmologica, vol. 117, pp. 785-790, 2010.

[17] P. J. Kertes and M. D. Conway, Clinical Trials in Ophthalmology, Lippincott Williams \& Wilkins, 1998.

[18] M. P. Delolme, B. Dugas, F. Nicot et al., "Anatomical and functional macular changes after rhegmatogenous retinal detachment with macula off," American Journal of Ophthalmology, vol. 153, pp. 128-136, 2012.

[19] J. Rojas, I. Fernandez, J. C. Pastor et al., "Development of predictive models of proliferative vitreoretinopathy based on genetic variables: the retina 4 project," Investigative Ophthalmology and Visual Science, vol. 50, no. 5, pp. 2384-2390, 2009. 


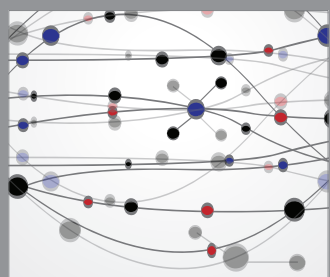

The Scientific World Journal
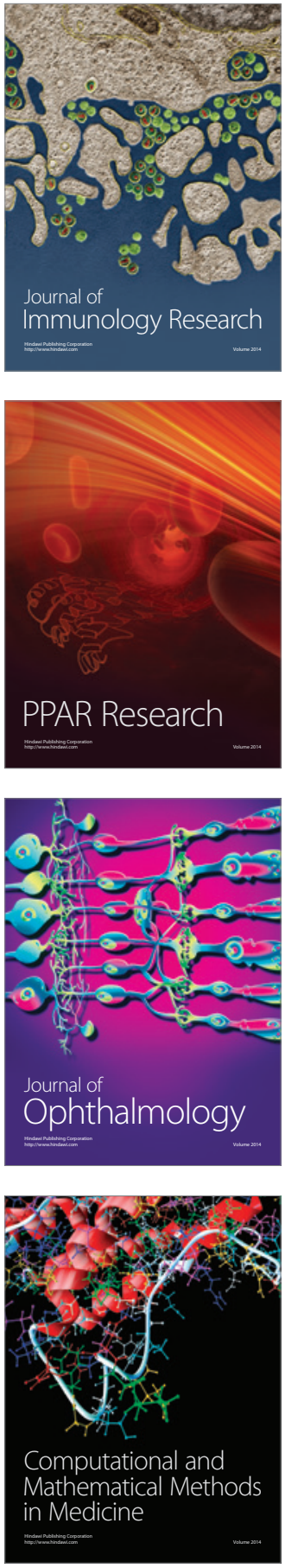

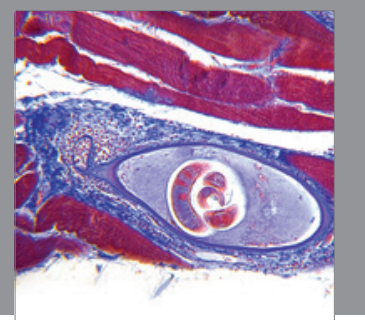

Gastroenterology

Research and Practice
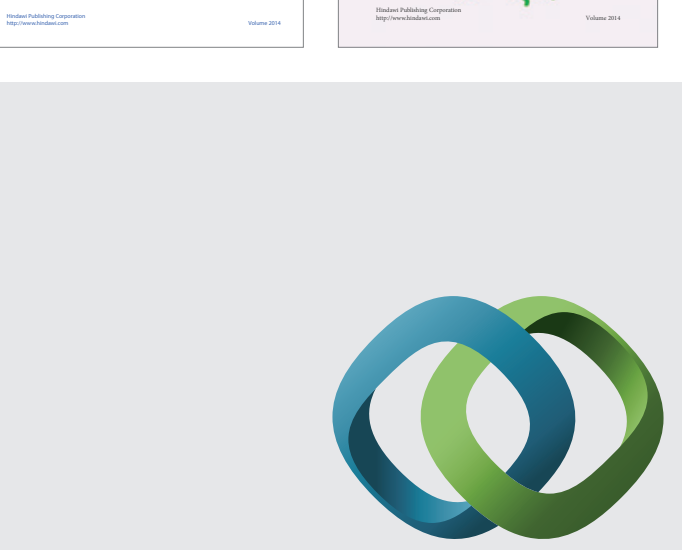

\section{Hindawi}

Submit your manuscripts at

http://www.hindawi.com
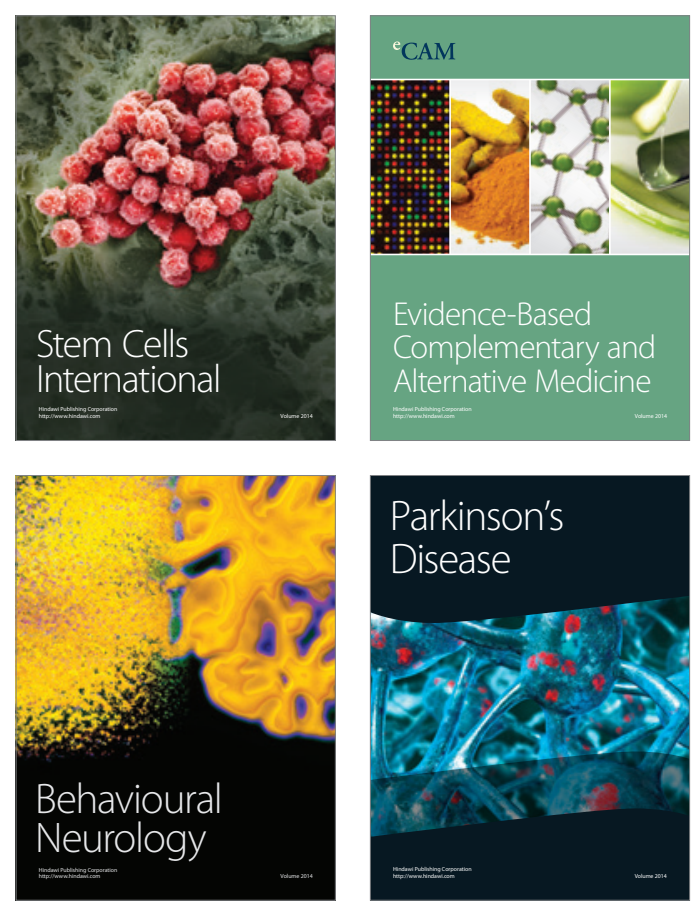

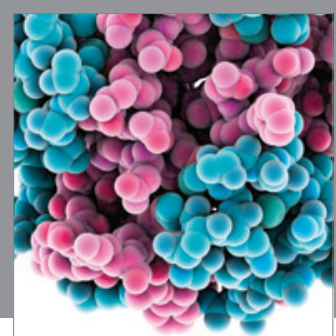

Journal of
Diabetes Research

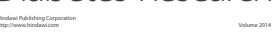

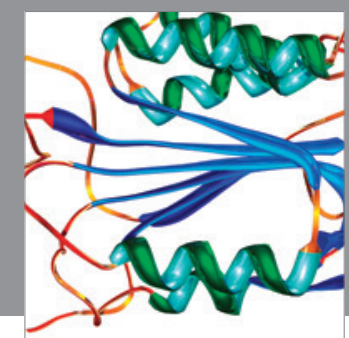

Disease Markers
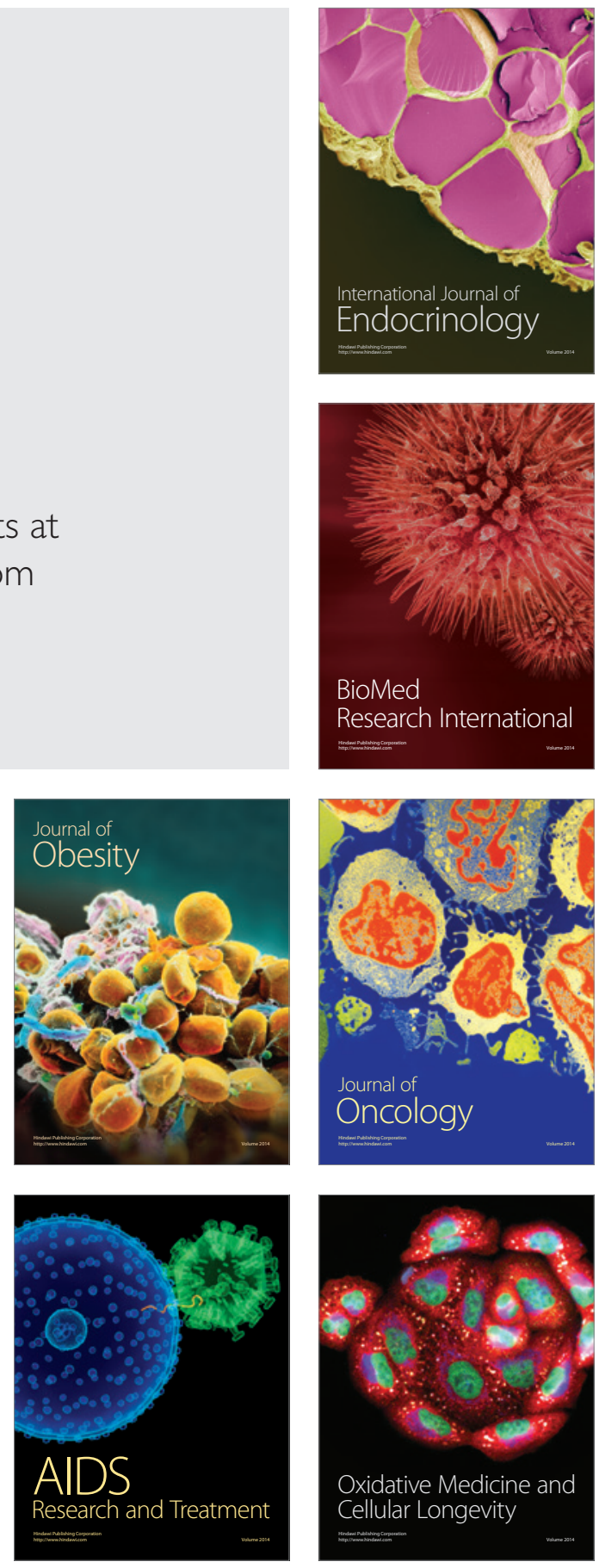